\title{
THE PALLIATIVE MEDICAL APPROACH TO THE MANAGEMENT OF HIV/AIDS PATIENTS
}

\author{
Selma Browde, $M B$ BCh, MMed Rad T \\ Palliative Medicine Institute, Broll Place, Sunnyside Office Park, Parktown, Fohannesburg
}

Golden Rule: There is always something you can do

This guideline will address the principles of the palliative care approach, emphasising patients with HIV|AIDS, and the management of pain and some selected symptoms.

Palliative care provides comprehensive care of the patient with the purpose of alleviating suffering. It includes the medical and nursing skills needed to alleviate physical pain and symptoms and also the skills needed to deal with emotional and psychosocial suffering of the patient and the family. It combines the art and the science of medicine.

The word 'palliate' means to alleviate, mitigate, make better. Until recently, because palliative medicine developed out of the hospice movement, palliative care was associated only with incurable or dying patients. However, it is being recognised that these skills should be available to all patients in need, whatever their disease. It is not logical to address the suffering of a patient only when that patient is dying; it has been shown that the outcome of any illness or surgical procedure is improved by the comprehensive management of the patient, which includes adequate alleviation of pain and distress, emotional as well as physical. For this reason the Palliative Medicine Institute has expanded the World Health Organisation (WHO) definition of palliative care, replacing the words 'for diseases that are no longer curable' with the expanded definition below:

'Palliative care provides active comprehensive care for the physical, emotional, psychosocial and spiritual suffering for the patient and the family. It starts at the moment of contact with the patient with any illness at any stage and continues for the duration of the illness. If and when the illness becomes incurable, palliative care then plays the major or total role.'

This philosophy is particularly important when managing HIVIAIDS patients, as it is essential that AIDS should not be regarded as a terminal illness. Giving good nutritional advice and hope, and especially preventing and treating any opportunistic infections vigorously, can enable a patient to enjoy a good quality of life for an extended period of time. Too often, patients are referred for terminal care when it is not truly indicated. AIDS patients form a large percentage of admissions to hospitals and clinics, and are seen at all stages in all settings. Therefore all doctors and nurses require guidelines on the approach and the skills of palliative care.

Palliative care promotes a new ethos in the doctor/nurse/patient relationship, which is patient- orientated and not disease-orientated, and requires non-judgemental attitudes of health personnel, important in all patients but especially those with HIV/AIDS. There is a need for a multidisciplinary team approach.

There are two parts to this guideline. Part 1 deals with the understanding of pain and its management, and Part 2 (to appear in the next issue of the Journal) with symptoms commonly associated with HIV/AIDS.

\section{PART 1: PAIN}

\section{INTRODUCTION}

Pain is an important clinical problem, too often poorly assessed and under-treated. There has been growing international recognition that pain is a neglected issue in both developed and developing countries alike.
Various reasons for poor pain control were reported by the World Health Organisation (WHO 1992). These included:

the inadequacy of medical education

unwarranted fear on the part of both doctors and nurses that strong pain killers are addictive and should not be taken until very late stages of the illness. As a result, they tend to under-prescribe or 
underdose analgesics, and

myths about morphine in particular are an important factor in the inadequate pain and symptom control so widely prevalent.

Further reasons for poor control of pain noted by palliative care doctors and nurses are:

not listening to what patients are trying to tell, and not giving enough time to the patient

waiting for the patient to complain instead of asking, and pre-empting the onset

failure to recognise that over half of patients have more than one pain

not consulting the relatives or the nurses dealing with the patient, who can provide valuable information, and

- lack of knowledge in diagnosing and managing the different pains.

\section{THE DEVELOPMENT OF MODERN PAIN MANAGEMENT}

Until the 1950s, the transmission of pain impulses was considered to be relatively uncomplicated and straightforward. The assumption was that the sensation of pain was achieved by a fixed direct-line communication, skin to brain in a straight-through fashion. It was also believed that the perception of pain was proportional to the intensity of the stimulus producing it, viz. major trauma causing more pain than minor injury, major surgery evoking more pain than a simple surgical procedure, or major illness causing more pain than a minor illness. It is now known that the transmission and perception of pain is a highly complicated process.

There is variation in perception of pain from one patient to another. This perception depends on the emotional state of the patient, and the fact that dealing with the emotions is an important part of pain management is explained by the pathophysiology, i.e. the mechanisms of pain. Pain should be adequately treated, because untreated or inadequately treated pain may have serious harmful effects on the body and therefore, under certain circumstances, can even kill.

\section{TYPES OF PAIN}

It is important to distinguish between the different types of pain, because often the management differs, and different drugs may be indicated.

Nociceptive pain Pain associated with tissue damage in illness or trauma due to stimulation of the nociceptors (nerve endings in skin and internal organs)
Neuropathic pain Pain associated with nerve damage, either compression or injury, or sympathetically mediated pain.

AIDS patients nearly always suffer from both types of pain, often simultaneously.

\section{Neuropathic pain}

Neuropathic pain usually has distinguishing physical features such as burning or stinging, sensation may be absent or abnormal, and patients may exhibit allodynia (pain exacerbated by light touch, e.g. the patient cannot bear clothing on the affected area). Neuropathic pain may be found in post-herpetic neuralgia and peripheral neuritis, both of which are common in people with AIDS.

Neuropathic pain is managed with different drugs from those described below in the general management of pain. It is usually treated with:

- antidepressants, usually amytriptyline (Tryptanol)

anticonvulsants, usually clonazepam (Rivotril) or carbamazepine (Tegretol).

Sometimes the addition of morphine is of value, although given alone morphine is not usually adequate for the treatment of neuropathic pain.

\section{DEFINITIONS OF PAIN}

Pain is an unpleasant sensory and emotional experience associated with actual or potential tissue damage.

Pain is always subjective - pain is what the patient says hurts.

\section{CLASSIFICATION OF PAIN}

$\begin{array}{ll}\begin{array}{l}\text { Type } \\ \text { Acute }\end{array} & \begin{array}{l}\text { Examples } \\ \text { Postoperative, trauma, acute } \\ \text { medical emergencies, procedural } \\ \text { Chronic back pain, trigeminal } \\ \text { neuralgia, phantom limb, post- } \\ \text { hepatic neuralgia }\end{array} \\ \begin{array}{l}\text { Painful conditions not } \\ \text { requiring acute } \\ \text { intervention }\end{array} & \begin{array}{l}\text { Cancer, AIDS or other painful } \\ \text { conditions }\end{array} \\ & \end{array}$

This classification is helpful as it distinguishes the approach to acute pain such as post-operative pain, trauma pain and procedural pain, which require special skills (see Guidelines for acute pain). In these situations one is usually dealing with an opiate-naïve patient who has an immediate need for high doses of analgesia, and therefore monitoring is necessary. With painful illnesses one usually is able to use 
a stepwise or ladder approach, incrementally increasing dosage, so there is no danger of respiratory depression. This method is described below, based on the WHO programme.

\section{PAIN IN AIDS}

Pain in AIDS is generally under-diagnosed and undertreated.

A variety of pain syndromes have been identified with HIV/AIDS.

-1. Eighty-five per cent of patients with AIDS pain are under-treated according to international surveys.

AIDS pain tends to be of more than one type and to involve more than one location. Neuropathic pain syndromes occur in up to $40 \%$ of AIDS patients.

- Treatment must be directed to the underlying cause if possible - therefore while managing the pain it is essential to identify any opportunistic infection and treat it vigorously.

N.B. It is important to remember that painful procedures must not be performed without appropriate analgesia. The choice of drug depends on the procedure and whether or not pain is expected to last after completion of the procedure. Local anaesthesia is often not adequate on its own.

This is especially important in babies and children (guidelines on procedural pain are available).

\section{PAIN MANAGEMENT}

Pain management usually requires a multi-modal approach. The aim is usually at progressive pain relief, with relief at night, relief at rest during the day, and relief on movement (not always completely possible).

In patients with AIDS constant review is most important, as the pain may no longer be present once an opportunistic infection has been cured and therefore the pain medication will need to be discontinued.

Pain control in both adults and children is made easy if approached scientifically and not haphazardly. The different dosage regimens are listed further on in this guideline.

Pain management can be considered under three headings:

Assesment

Therapeutic strategy

둘 Continuing care

\section{ASSESSMENT}

This is an important preliminary step.
It is important to remember the principles of the palliative approach regarding attitude to the patient and not to judge. Only the patient can know how he or she feels.

Do not withhold analgesia while assessing and planning the therapeutic strategy.

- Believe the patient's complaint

- Take a careful history

- Perform a thorough medical and neurological examination

- Assess the emotional state of the patient

Assess the psychosocial status of the patient

Evaluate non-verbal behaviour, e.g. facial expression and body language

-1 Treat the pain while doing the diagnostic work-up

- Personally review any diagnostic investigations

- Score the pain using pain measurement scales

- Chart painful areas on body charts.

Note that in very young children the non-verbal evaluation and believing the parent or caregiver may be the primary focus.

\section{Scoring pain}

Pain must be scored daily and recorded on the patient's chart just as temperature and pulse rate are. In addition patients when at home should also record their pain scores, medication taken, time of administration, and any sideeffects. This assists compliance.

Adults: Visual analogue scale:

no pain

worst pain imaginable.

Children: Faces scale: The child chooses the face representing his/her feeling.
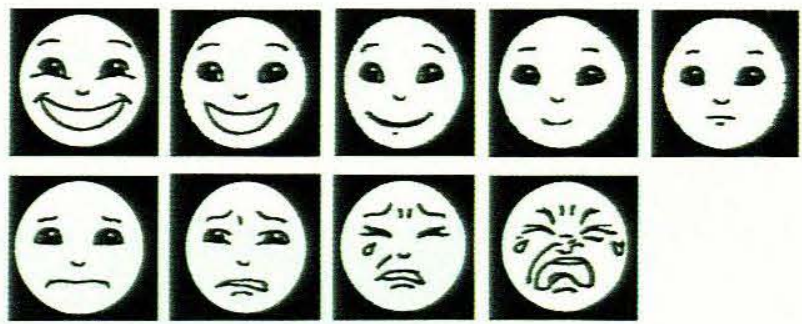

The approach to pain relief in children requires a specific approach which differs from adults. Guidelines for the relief of pain in children are available.

\section{THERAPEUTIC STRATEGY}

After assessment the next step is to consider the different therapeutic approaches, namely drug therapy, non-drug therapy, and behavioural techniques. These can be used concurrently or sequentially and need to be adapted to the needs of the individual patient. 


\subsection{Drug therapy}

The correct use of drugs provides pain relief for about $80 \%$ of patients. The WHO has provided a simple and inexpensive programme based on the concept of:

aright drug

right dose

right time

right route.

\subsubsection{The right drug}

The choice of drugs is determined by the severity, site and type of pain. The selection of a drug is made easier by the use of the 'three-step ladder' or 'analgesic ladder'. The three steps of the ladder represent mild, moderate and severe pain, and the appropriate drugs to use for each step are indicated in the diagram.

\begin{tabular}{|c|c|c|}
\hline \multicolumn{3}{|c|}{ The three-step ladder } \\
\hline $\begin{array}{l}\text { Step } 3 \\
\text { Severe pain }\end{array}$ & \multicolumn{2}{|c|}{$\begin{array}{l}\text { Strong opioid } \\
\pm \text { Non-opioid } \\
\pm \text { Adjuvant }\end{array}$} \\
\hline $\begin{array}{l}\text { Step } 2 \\
\text { Moderate pain }\end{array}$ & $\begin{array}{c}\text { Weak opioid } \\
\pm \text { Non-opioid } \\
\pm \text { Adjuvant }\end{array}$ & $\begin{array}{l}\text { Pain } \\
\text { persisting } \\
\text { or increasing }\end{array}$ \\
\hline $\begin{array}{l}\text { Step } 1 \\
\text { Mild pain }\end{array}$ & $\begin{array}{l}\text { Non-opioid } \\
\pm \text { Adjuvant }\end{array}$ & Pain \\
\hline
\end{tabular}

\section{First step of the ladder - mild pain}

The use of a non-opioid preparation such as paracetamol, aspirin or a non-steroidal anti-inflammatory agent is suggested. Adjuvant drugs such as an anxiolytic, a sedative or an anti-emetic may be used. If the effect of the antiinflammatory agent alone is not adequate, paracetamol may be added before moving to the next step of the ladder.

\section{Second step of the ladder - moderate pain}

Weak opioid preparations such as codeine may be prescribed with or without an adjuvant. A drug from the first step of the ladder may be used together with the codeine.

If the pain persists, or increases, and the maximum dose has been reached and given at the right time intervals, one must move to the next step of the ladder.

If a drug used in the maximum dose at the right time interval ceases to be effective it is important not to switch to another drug on the same step of the ladder of similar strength. It is never too soon to move to the third step if the second-step drugs are not controlling the pain.

A very useful drug between step 2 and step 3 is tramadol. It is important to proceed cautiously with this drug. The starting dose is higher in patients who have previously received opioids.

\section{Third step of the ladder - severe pain}

If the second-step drugs cease to be effective, a strong opioid, usually morphine, should be prescribed. For very short periods of time the intramuscular route may be convenient, e.g. in acute episodes of pain, but for any extended period of time morphine should be given orally. Pethidine is contraindicated for long-term pain and should only be used for acute, short-term pain.

Internationally there is much ignorance surrounding the use of morphine, and as a result, many patients endure unnecessary pain.

It is important to control the side-effects of morphine:

- Constipation. Do not start morphine without giving stool softeners and ongoing laxatives.

Nausea. This is fairly common but can usually be controlled with an anti-emetic. If it persists, change from 4-hourly to continuous infusion by a subcutaneous syringe driver. This may control the nausea.

\section{Control-release morphine sulphate (MST)}

Should be initiated by a medical doctor. When the analgesic dose of morphine syrup has been reached the MST dose can be calculated. This is done by dividing the total 24-hour dosage of morphine syrup by 2, which will give the twice-daily dose of MST required to control the pain. In addition, always prescribe for breakthrough pain using a short-acting oral morphine. If starting with MST $a b$ initio, start with $10 \mathrm{mg}$ bd, but expect breakthrough pain and increase daily until almost no breakthrough doses are needed. (In rare cases as much as $1000 \mathrm{mg}$ over 24 hours may be needed.)

\section{Morphine sulphate injection}

Injections should only be administered to patients who cannot swallow, are very ill or vomiting, or whose pain is not controlled by oral morphine. Never utilise the intramuscular injection route for long-term use. It is preferable to use the rectal route (use the oral dose). MST tablets can be used rectally but must never be crushed. The adult dose for intramuscular injections is $10-15 \mathrm{mg}$ 4-hourly for adults.

Other opioids may be used if there is morphine intolerance, which may occur in a minority of patients, presenting as:

- persistent vomiting not relieved by powerful antiemetics or changing to the subcutaneous route using a syringe driver 
Myths about morphine

$\begin{array}{ll}\text { Myth } & \text { Fact } \\ \text { Addiction } & \begin{array}{l}\text { Not addictive if given for pain. Pain is an } \\ \text { antagonist to morphine. }\end{array}\end{array}$

Respiratory If morphine is given incrementally, using depressant the three-step-ladder, starting with low dosages and small increments, it does NOT cause respiratory depression. This is very different from the postoperative situation where one has to start with high doses in a morphine-naïve patient, necessitating close monitoring of the patient.

Too soon to start It is never too soon to start if the patient is not controlled on the second step of the ladder. If necessary patients can be maintained on morphine for many years and lead a normal life.

Maximum dose Unlike the non-opioids and weak opioids there is no maximum dose for morphine when given incrementally and orally or by syringe driver. Morphine is also available in a slow-release tablet formulation and can also be injected subcutaneously in long-term use. This makes morphine a most valuable drug.

Drowsiness This only lasts the first few days, is transient, and has no effect on mental functioning thereafter.

- persistent sedation that does not wear off after a week

symptoms relating to histamine release (pruritus, bronchoconstriction) that do not respond to antihistamines, and

very rarely - psychotic symptoms. Not to be confused with hallucinations due to accidental administration of much more that the prescribed dose. Note that using the incremental dosage regimen one cannot cause a patient's death with morphine, as used this way respiratory depression does not occur.

Alternative opioids:

Fentanyl. Duragesic patch - start with a low dose and increase slowly, preferably after dose requirement has been established with morphine syrup. Use the equivalent dosage table as fentanyl is much more potent than morphine. If a patient is morphine-naïve, start with a $25 \mu \mathrm{g}$ patch. Warning: The patch should be prescribed only by persons knowledgeable in the continuous administration of fentanyl.
Methadone requires great care in administration, and detailed instructions are necessary. It is generally longeracting than morphine and is more potent.

Bupremorphine should be taken sublingually and should never be given with other opioids as it is a mixed agonistantagonist and will reverse analgesia. It is much more potent than morphine and effects last for 6 - 9 hours. It has a ceiling effect, and is not a complete alternative to morphine.

\subsubsection{The right dose}

Dosages need to be individualised. The correct dose is that dose which gives relief for at least 3 and preferably 4 hours.

Get to know a few drugs well in order to be familiar with maximum doses and possible drug interactions.

There is an upper limit or maximum dose for the commonly used analgesics. Provided morphine is prescribed incrementally, until pain relief is obtained, there is no maximum dose. The correct dose of morphine is therefore the dose that relieves the pain.

Note: see no. 3 'Continuing care' for suggested dosages for adults and suggested drug dosages in children.

\subsubsection{The right time}

Drugs should be given 'by the clock', i.e. at regular intervals.

They should never be prescribed 'as required'. The aim in pain control is to maintain therapeutic concentrations of drug to control the pain. One would not consider prescribing antibiotics 'as required.' A similar principle should be applied for the relief of pain.

One of the factors in the advance in pain relief is the principle of giving the next dose before the recurrence of the pain. Waiting for the pain to recur before administering the drug means that higher doses of analgesic are required and the pain is more difficult to control.

- Few analgesic drugs have a half-life of more than 4 hours, so that 4-hourly and not 6-hourly administration should be the rule. A 'break-through dose' should always be prescribed while titrating the dose against the pain. It may take some time before the adequate 4-hourly dose is reached.

\section{THE RIGHT TIME}

- Never prescribe PRN (as required)

- Usually given 4-hourly

- Always prescribe a break-through dose

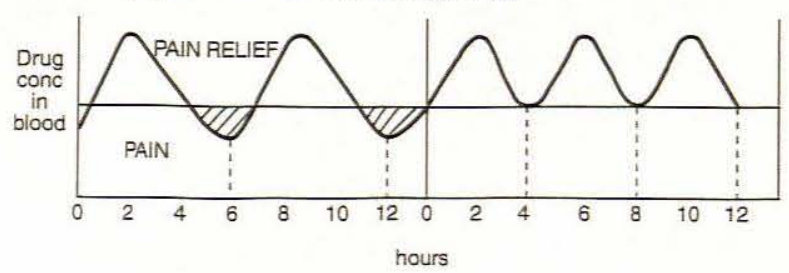




\subsubsection{The right route}

- Medication by the oral route is preferable where possible. Alternative routes may become necessary during the course of the disease.

- Subcutaneous administration is extremely valuable. The dose is the same as the intravenous dose (not the oral dose). A syringe-driver enables patients who cannot swallow, are not well controlled, or wish to be comfortable in the terminal phase to live a good quality of life. If a syringe driver is not available, a butterfly needle inserted subcutaneously is invaluable, using a syringe to administer the medication, analgesics or sedatives. The needle may be left in situ and the dose of morphine injected 4-hourly together with an antiemetic or anxiolytic. The site of insertion of the needle must be monitored and usually needs to be changed every $3-5$ days. This method is very useful for fluid replacement in dehydration, a technique known as hydrodermoclysis, and is also useful in the emergency situation when the intravenous route is unattainable.

- The rectal route may be used if no diarrhoea is present. Note that morphine sustained-release tablets (MST) may be given rectally, but never crush the tablets as they are slow-release.

- The buccal or sublingual route can also be used.

- The transdermal route is also an option. Attention must be given to incremental dosing when using Duragesic patches (see Warning on fentanyl above).

- The intramuscular route should not be used for longterm pain control.

- The intravenous route is seldom used. A subcutaneous syringe driver is preferable.

\subsection{Non-drug therapy}

- Radiotherapy may be important in bony lesions, spinal cord compression, and fungating malodorous malignant lesions

- Nerve blocks

- Acupuncture

- Transcutaneous electrical nerve stimulation

Trigger point injections

- Physiotherapy

- Techniques such as reflexology and aromatherapy are often valuable

- Neurosurgical approaches (seldom used nowadays).

It is clear that a multidisciplinary team should be involved in making decisions regarding non-drug therapy.

\subsection{Behavioural techniques}

Various behavioural techniques are available which are provided in conjunction with counselling by psychologists or counsellors or traditional healers:
- Meditation

Visualisation

- Art and music therapy

- Aromatherapy

- Reflexology

- Stress reduction therapy.

It is important to consider the role of the traditional healer, especially in the field of HIV/AIDS. The traditional healers who are prepared to work with doctors and nurses are playing an increasingly important role in medicine in South Africa and could be a useful member of a multidisciplinary team. They would have an important role, not only in the management of pain but also in dealing with the emotional welfare of the patient and family.

\section{CONTINUING CARE}

\section{Reassessment}

A continuing necessity

Old pains may get worse and new ones may develop

Review Review Review Review

\section{SUGGESTED DOSAGE REGIMENS - ADULTS}

Mild pain (first step of the ladder)

Non-opioids

\begin{tabular}{|c|c|c|}
\hline Drug & Suggested dosage & Side-effects \\
\hline Paracetamol & $\begin{array}{l}\text { Paracetamol } 0.5-1 \mathrm{~g} \text { 4-hourly, } \\
\text { maximum } 6 \mathrm{~g} \text { in } 24 \text { hours } \\
\text { Effectiveness: limited }\end{array}$ & Liver toxicity \\
\hline Aspirin & $\begin{array}{l}250-1000 \text { mg every } \\
4-6 \text { hours } \\
\text { Do not use with other anti- } \\
\text { inflammatory } \\
\text { agents. }\end{array}$ & $\begin{array}{l}\text { Gastro-intestinal } \\
\text { disturbance (GI) } \\
\text { Faecal blood loss } \\
\text { Hypersensitivity }\end{array}$ \\
\hline Ibuprofen & $\begin{array}{l}200 \text { - } 600 \mathrm{mg} 3-4 \text { times per } \\
\text { day after food, } \\
\text { Discontinue or add another } \\
\text { analgesic if not effective. If } \\
\text { patient cannot swallow, } \\
\text { non-oral routes may be used. }\end{array}$ & Gl disturbance \\
\hline
\end{tabular}

\section{Moderate pain (second step of the ladder)}

Weak opioids (often used in combination with nonopioid analgesics)

$\begin{array}{lll}\text { Drug } & \text { Suggested dosage } & \text { Side-effects } \\ \begin{array}{l}\text { Codeine phosphate - } \\ \text { drug of choice }\end{array} & 30-60 \mathrm{mg} 4 \text {-hourly } & \begin{array}{l}\text { Constipation } \\ \text { Nausea }\end{array} \\ \begin{array}{l}\text { Use alone or in } \\ \text { combination with: }\end{array} & \\ \begin{array}{l}\text { paracetamol } \\ \text { or }\end{array} & 500 \mathrm{mg} \text { 4-hourly (orally) } \\ \text { aspirin } & 250-500 \mathrm{mg} \text { (orally) }\end{array}$




\section{Severe pain (third step of the ladder)}

Strong opioids are required for most patients with severe pain. Morphine is the treatment of choice, preferably administered orally.

Drug $\quad$ Dose
$\begin{array}{ll}\text { Morphine Starting dose } \\ \text { syrup }\end{array}$
$\begin{aligned} & \text { Depends on severity of pain } \\ & \text { and whether patient has } \\ & \text { been on codeine previously } \\ & \text { Opioid-naive: } 5 \text { - } 10 \mathrm{mg} \\ & \text { 4-hourly } \\ & \text { Non-opioid-naïve: } 15 \mathrm{mg} \\ & \text { 4-hourly } \\ & \text { Titrate to analgesic response } \\ & \text { Elderly adults and in patients } \\ & \text { with severe liver impairment: } \\ & \text { 2.5 - } 5 \text { mg 4-hourly }\end{aligned}$

Side-effects

Nausea (prescribe antiemetic concurrently) Constipation (always prescribe laxatives concurrently)

Drowsiness (if excessive after the first dose and the patient is pain-free, halve the dose)

Dose increases

Allow 24 hours before considering increasing the dose in order to allow time for a steady state to have been reached. If patients do not experience any relief, increase dose by $30-50 \%$. There is no maximum dose; this includes children. Increase dosage incrementally until an analgesic response is achieved. Double the dose at night $(22 \mathrm{hOO})$ to minimise sleep disturbances. If patient has pain within dosing intervals, extra breakthrough doses must be prescribed.

\section{PAEDIATRIC PALLIATIVE CARE}

\section{GUIDING PRINCIPLES}

There is a great need to promote and enable more palliative care so that all children, and their families, will achieve the best possible quality of life. An immediate priority is symptomatic management, including pain relief for paediatric AIDS patients, and support and assistance for their families and care-givers.

The WHO/International Association for the Study of Pain (IASP) guidelines express the consensus that pain relief is an essential component to managing children with cancer, AIDS and other conditions. All children should be managed with a palliative care approach which includes pain prevention and relief, and all health workers should integrate the following guidelines into their daily practice.

\section{Major types of pain in children}

pain caused by disease

- pain caused by procedures, e.g. finger prick, venepuncture, injection, lumbar puncture, bone marrow biopsy/aspirate, changing dressings, inserting central lines, any other painful procedure

- pain caused by incidental trauma, and

other childhood pains.

\section{Barriers to pain control in children}

anfounded fear of addiction

- underdosing of opioid analgesics

- misunderstanding of pharmacokinetics of opioids in children

E inadequate doses at inappropriate intervals, by painful or less effective routes

- lack of knowledge of children's perception of pain and illness

ailure to evaluate all factors properly - this may contribute to pain and inadequate treatment

- lack of knowledge that all children, irrespective of mental state, e.g. semi-comatose, or sometimes comatose, meningismus, brain-damaged etc., perceive pain and require the same approach, and

- lack of information about simple behavioural, cognitive and supportive techniques that can be taught to patients and/or their families.

\section{WHO Clinical Recommendations for Pain Control in Children}

- Severe pain in children is an emergency. Supportive therapies should be combined with appropriate drug treatment.

- Assess at regular intervals.

Where possible, the cause of pain should be determined.

- Procedure pain should be treated aggressively.

- The analgesic ladder should be used.

- Anticipate side-effects and treat aggressively.

- When opioids are reduced or stopped doses should be tapered gradually to avoid severe pain flare.

Do not stop giving the opioid if child becomes comatose. Pain can still be perceived in the comatose state.

Pain may be difficult to assess in children. The parent may be the most important person to involve when assessing pain in infants or toddlers. If health care workers are unsure whether behaviour indicates pain, and if there is reason to suspect pain, an analgesic trial can be diagnostic as well as therapeutic.

\section{SUGGESTED DRUG DOSAGES IN CHILDREN}

\section{Step 1 of the ladder - mild pain}

\section{Non-opioid analgesics}

Paracetamol syrup po $15-20 \mathrm{mg} / \mathrm{kg} /$ dose 6 -hourly (in neonates: maximum dose is $60 \mathrm{mg}$ per 24 hours)

1 - 5 years: $250 \mathrm{mg} 4$ - 6 -hourly

5 - 12 years: 250 - $500 \mathrm{mg} 4$ - 6-hourly

(Paracetamol suppositories may be used instead of syrup.)

Maximum dose: $90 \mathrm{mg} / \mathrm{kg} / 24$ hours. 
Ibuprofen syrup ( $100 \mathrm{mg} / 5 \mathrm{ml}) 10 \mathrm{mg} / \mathrm{kg} /$ dose once or twice daily. Do not exceed $500 \mathrm{mg} /$ day or $5-6 \mathrm{mg} / \mathrm{kg} \mathrm{6-}$ hourly.

Paracetamol and ibuprofen can be given together to improve analgesia.

\section{Step 2 of the ladder - moderate pain}

\section{Weak opioids}

Valoron (tilidine $\mathrm{HCl}$ ). A very useful opioid analgesic administered orally/mucosally at the dose of $1 \mathrm{mg} / \mathrm{kg} / \mathrm{dose}$. The traditional dose of 'one drop per year' tends to underdose the younger patient. Each drop contains $2.5 \mathrm{mg}$, so take the body weight of the child, divide by 2.5 and this gives you the number of drops to give the patient. It is bitter so it should be administered with a syrup, sugar or honey.

Codeine. Dose: 0.5 - $1 \mathrm{mg} / \mathrm{kg}$ dose 4 - 6-hourly.

(Parenteral codeine has 2 major problems: very painful on intramuscular injection and has a very high incidence of anaphylaxis when given intravenously, so is not recommended.) In South Africa many oral formulations contain codeine, and this provides a very good adjunct to paracetamol for moderate pain relief. There does appear to be a ceiling to the analgesic effect, after which an increase in the dosage does not result in more analgesia, but merely an increase in the side-effects of sedation, pruritus and urinary retention.

Combinations (among many others):

- Stopayne syrup: paracetamol + codeine + promethazine (Phenergan)

- Myprodol syrup: paracetamol + codeine + ibuprofen

- Newer combinations using paracetamol and a nonsteroidal anti-inflammatory drug (NSAID) without codeine.

\section{Step 3 of the ladder - severe pain}

\section{Strong opioids}

\section{Commonly used opioids are:}

\section{Morphine:}

$I V I$ - bolus: $0.1 \mathrm{mg} / \mathrm{kg} /$ dose 3 - 4-hourly

IVI - infusion: 5 - $40 \mu \mathrm{g} / \mathrm{kg} /$ hour (mix $0.5 \mathrm{mg} / \mathrm{kg}$ morphine in $50 \mathrm{ml}$ of normal saline in a syringe and run the infusion at $0.5-4 \mathrm{ml} / \mathrm{h}$ which will deliver 5 to $40 \mu \mathrm{g} / \mathrm{kg} / \mathrm{hour}$ of morphine)

\section{Morphine oral starting dose:}

$>1$ year $0.2-0.4 \mathrm{mg} \quad 4$-hourly

1 - 5 years $0.5 \mathrm{mg}-5 \mathrm{mg}$ 4-hourly

$6-12$ years $5-7.5 \mathrm{mg} \quad 4$-hourly

Note:

- Use lower starting doses for younger children within the age ranges.

- Increase dose requirement: allow 24 hours before considering dose increase. Increase dose by $30-50 \%$.

No maximum dose.

Titrate to analgesic response.

- If child has pain within dosing interval extra breakthrough doses must be prescribed.

\section{Meperidine (pethidine):}

IVI infusion not recommended: metabolites of pethidine may accumulate and may cause convulsions.

\section{Additional notes on opioids:}

- Intravenous morphine should only be used in a hospital or hospice setting.

Opioids have other advantages, i.e. can alleviate intractable diarrhoea and cough and distressing dyspnoea in AIDS.

Note: provision exists in the Essential Drug Program for oral morphine to be available at primary care clinics.

Note: Respiratory distress in infants and children should be managed by the administration of morphine according to body weight. Incrementally increase the morphine if found to be inadequate, but unlike use for pain, doses for respiratory distress are low.

\section{Neuropathic pain in children}

- Secondary analgesics can be used, e.g. for post-herpetic neuralgia, peripheral neuritis, etc.

- Antidepressants - amitriptyline. Start with low doses.

- Anticonvulsants - clonazepam (Rivotril): < 1 year start with 1 drop nocte increase to bd.

1 - 5 years start with 6 - 12 drops nocte increase to a maximum of 15 drops daily. 